\title{
Inserção de um Agente Indutor da Relação Universidade- Empresa em Sistema de Inovação Fragmentado
}

\author{
Marcos Cerqueira Lima \\ Francisco Lima Cruz Teixeira
}

\section{RESUMO}

O objetivo deste trabalho é explorar como se inseriu o Instituto Euvaldo Lodi - Núcleo Regional Bahia, enquanto agente indutor do relacionamento Universidade-Empresa, no Sistema Estadual de Ciência e Tecnologia, entre 1996 e 1998. Para tanto, é feita uma caracterização de aspectos pontuais do sistema baiano de inovação, ambiente em que se insere o agente indutor. Esta caracterização adota como perspectiva o prisma analítico dos três principais atores envolvidos no processo de inovação: o setor produtivo, ou seja, como este organiza o trabalho intrafirma e desempenha trocas interfirmas; o Estado, condições de financiamento e políticas públicas; e a situação dos centros de ensinopesquisa. Delineado este cenário, são apresentados os programas do instituto que buscam aproximar o conhecimento universitário da prática empresarial na Bahia, visando à criação de condições favoráveis à inovação tecnológica. Conclui-se que, apesar do limitado potencial inovativo de ambientes tecnologicamente fragmentados, a indução de agentes como o Instituto Euvaldo Lodi pode facilitar a interação de empresas e universidades, criando ambiente propício a trocas de informações e organização de projetos cooperativos e consultorias.

Palavras-chaves: relação universidade-empresa; sistemas locais de inovação; políticas de ciência e tecnologia; IEL.

\begin{abstract}
The objective of this work is to explore the context in which the Instituto Euvaldo Lodi has induced University-Enterprise relations within the local Science and Technology System in Bahia, Brazil, between 1996 and 1998. In order to do so, the authors analyses a few relevant aspects of the Brazilian Innovation System and its Bahia sub-system. Such analysis takes into account three basic points of view: that of the productive sector (i.e., how the intra-firm work is organized and how inter-firm exchanges affect the system), that of the State (financial support and public policies) and that of the research and higher education institutions. Against this background, the authors describes the IEL programs for bridging university knowl-edge and entrepreneurial practice in Bahia, aiming at creating better conditions for technological innovation. Among the main conclusions of this dissertation is the realization that, in spite of the limited potential of innovation in technologically fragmented environments, the bridging work of agents such as IEL may promote specific interactions between enterprises and universities, creating an environment in which information exchange, cooperative projects and consulting activities may be stimulated.
\end{abstract}

Key words: university-enterprise relationship; local innovation systems; science and technology policy; IEL. 


\section{INTRODUÇÃO}

O presente trabalho se propõe descrever a atuação do Instituto Euvaldo Lodi Núcleo Regional Bahia (IEL-BA) enquanto indutor da relação UniversidadeEmpresa (U-E) e identificar aspectos institucionais do contexto de C\&T no qual ele se insere, abordando as alternativas aí encontradas para a aproximação entre academia e setor produtivo. A partir dessa experiência de intermediação nos últimos três anos, pretende-se obter uma visão das possibilidades de tal articulação em contextos científico-tecnológicos pouco desenvolvidos. Esta seção abordará os principais conceitos teóricos utilizados para a caracterização do sistema de C\&T baiano.

\section{Relaçőes Universidade-Empresa}

O papel das universidades na dinâmica inovativa das sociedades tecnologicamente avançadas parece estar em transformação. Etzkowitz (1993) considera que "a atual participação da universidade no desenvolvimento econômico, incorporando-o como função acadêmica, junto com o ensino e a pesquisa, constitui a Segunda Revolução Acadêmica, cuja palavra-chave é 'capitalização do conhecimento'. A Primeira Revolução, ocorrida no final do século XIX, tornou a pesquisa uma função universitária, ao lado da tarefa tradicional do ensino".

A respeito dos motivos que levaram os governos, empresas e universidades de vários países a dedicar recursos crescentes à promoção de arranjos cooperativos interinstitucionais nas duas últimas décadas, Plonski (1994) escreve:

"da parte das universidades, a cooperação é percebida, entre outros, como uma forma de superar a insuficiência das fontes tradicionais de recursos, e assim manter essas instituições nos níveis desejados de ensino e pesquisa; da parte das empresas, a cooperação é percebida como capaz de prover uma solução para a dificuldade de lidar sozinha com os desafios multidimensionais da inovação [...], além do tradicional interesse em ganhar acesso privilegiado no recrutamento de talentos jovens; e da parte do Governo, a cooperação é percebida como estrategicamente importante para a viabilidade econômica e social de regiões e de nações, no novo paradigma econômico".

Plonski (1994) destaca ainda que, embora esta temática possa "ser remontada pelo menos ao começo deste século", o interesse pela interação do setor produtivo 
com a academia ganhou mais força em fins da década de 70 nos países centrais e, uma década mais tarde, nos periféricos. À medida que a geração de riqueza se torna mais atrelada à capacidade de gerar novos conhecimentos, o papel da pesquisa básica e a visão privilegiada do estado da arte que se detém na academia ganham importância para as empresas. O efeito destas transformações se faz sentir nas universidades em todo o mundo, estimulando e incrementando o espírito de "empreendedorismo científico" (Stal, 1994). A respeito das forças que levaram a estas transformações, Velho (1996) afirma:

"as relações entre as universidades e as empresas resultaram tanto de pressões externas à universidade como de decisões dos próprios pesquisadores. Como exemplo de pressões externas, Etzkowitz [1991] aponta a mudança nos padrões do financiamento da pesquisa acadêmica, ocorrida em função da redução das verbas estatais. Sem os tradicionais recursos do Estado, os pesquisadores são premidos a superar o medo de que o atrelamento ao setor privado pudesse comprometer a autonomia de suas atividades, ao tempo que os empresários começam a vislumbrar nas pesquisas acadêmicas um importante filão dos conhecimentos que eles precisavam para sobreviver num mercado cada vez mais competitivo".

Bonaccorsi e Piccaluga (1994) propõem uma taxonomia de interação U-E, cujo mérito está na simplicidade e abrangência. Os autores utilizaram como critérios de categorização o grau crescente de comprometimento de recursos, duração do relacionamento e formalização dos acordos. O Quadro 1 apresenta a classificação de Bonaccorsi e Piccaluga (1994), conforme tradução de Reis (1998).

\section{Quadro 1: Classificação das Relações U-E}

\begin{tabular}{|l|l|l|}
\hline \multicolumn{2}{|c|}{ TIPO } & \multicolumn{1}{c|}{ EXEMPLOS } \\
\hline A & RELAÇÕES PESSOAIS INFORMAIS & $\begin{array}{l}\text { Consultoria individual por acadêmicos, fóruns de integração, } \\
\text { workshops, ex-acadêmicos empresários (spin-offs). }\end{array}$ \\
\hline B & RELAÇÕES PESSOAIS FORMAIS & $\begin{array}{l}\text { Intercâmbio de pessoal, especialização de funcionários nas } \\
\text { universidades. }\end{array}$ \\
\hline C & INSTITUIÇÃO DE LIGAÇÃO & $\begin{array}{l}\text { Relação de parceria via terceiros (intermediários da ligação), sob } \\
\text { a forma de associações industriais (como corretoras), institutos } \\
\text { de pesquisa aplicada. }\end{array}$ \\
\hline D & $\begin{array}{l}\text { ACORDOS FORMAIS COM } \\
\text { OBJETIVOS ESPECÍFICOS }\end{array}$ & $\begin{array}{l}\text { Pesquisas contratadas, treinamento periódico, pesquisa } \\
\text { cooperativa, desenvolvimento de protótipos e testes. }\end{array}$ \\
\hline E & $\begin{array}{l}\text { ACORDOS FORMAIS TIPO } \\
\text { GUARDA-CHUVA }\end{array}$ & $\begin{array}{l}\text { Sem objetivos específicos; patrocínio da indústria para P\&D nos } \\
\text { departamentos universitários; doações privadas para pesquisa. }\end{array}$ \\
\hline F & $\begin{array}{l}\text { CRIAÇÃO DE ESTRUTURAS } \\
\text { PRÓPRIAS PARA A INTERAÇÃO }\end{array}$ & $\begin{array}{l}\text { Parques tecnológicos, incubadoras de empresas, consórcios de } \\
\text { pesquisa. }\end{array}$ \\
\hline
\end{tabular}

Fonte : Bonnacorsi e Piccaluga (apud Reis, 1998, p. 32). 
Deve-se notar que a partir do grau $\mathrm{C}$ de formalidade na interação, surge a necessidade de "instituições-ponte" (Cassiolato, 1996), geralmente terceiros na relação, que ajudam a contornar barreiras culturais, logísticas e financeiras à cooperação. O objeto de estudo deste trabalho, o IEL - BA, se propõe exercer este papel. A importância de instituições de ligação é tão maior quanto menos espontânea for a aproximação entre a academia e o setor privado, como é o caso do incipiente Sistema Brasileiro de Inovações (Albuquerque, 1996).

\section{Sistemas Nacionais de Inovação}

As relações U-E não podem ser analisadas fora de um contexto sócio-econômico-institucional mais amplo (Cassiolato, 1996). Diversos autores, sobretudo Freeman (1987), Lundvall (1992) e Nelson (1993), contribuíram para a formação de um instrumental de inspiração evolucionista, os Sistemas Nacionais de Inovações (SNIs), cuja abordagem institucionalista acomoda a análise de arranjos geradores e difusores de inovação, tais como os arranjos cooperativos entre universidades e empresas. Lundvall (1992) define os SNIs como sendo "constituídos de elementos e relações que interagem na produção, difusão e uso de conhecimento novo e economicamente útil". De forma ampla, este processo envolve "todas as partes e aspectos da estrutura econômica e sua configuração que afetam o processo de aprendizado nas empresas e entidades tecnológicas, o que inclui os subsistemas de produção, de marketing e de finanças" (Lundvall, 1992).

Segundo estudos sistematizados por Lundvall (1992), os principais elementos do sistema são estes: (1) a organização interna das firmas, englobando a maneira como se dá o fluxo de trabalho, as políticas promocionais, interação da base produtiva com departamentos de P\&D e marketing etc. (Gjerding, 1992); (2) relacionamentos entre firmas, incluindo relação produtor-usuário, redes de relacionamento e distritos industriais (Gelsing, 1992); (3) a configuração do setor financeiro, envolvendo a disponibilidade de crédito, capital de risco e programas de incentivo à inovação (Christensen, 1992); (4) o setor público, enquanto entidade de regulação e estabelecimento de padrões e normas, orientando, mediante políticas públicas, a direção das tendências de inovação de um país (Gregersen, 1992); e (5) estrutura de ensino e organização de P\&D, tida como um dos principais insumos do processo de inovação (Freeman, 1992). Esses elementos serão utilizados como referencial de análise para caracterização do Sistema de C\&T da Bahia, no qual se insere a instituição-ponte analisada, o Instituto Euvaldo Lodi. 


\section{A Fragmentação do Sistema Nacional de Inovação Brasileiro e a Relação U-E no Brasil}

Albuquerque (1996) desenvolveu uma classificação que distingue sistemas de inovação dos tipos líderes, difusores e fragmentados. Os principais critérios de distinção estão relacionados à variável pesquisa e desenvolvimento (P\&D), a saber: (1) prioridade nacional conferida ao item $\mathrm{P} \& \mathrm{D}$, em termos da participação destes gastos no total do PIB; (2) alto empreendedorismo tecnológico do setor privado, medido como a participação de empresas privadas nos gastos de $\mathrm{P} \& \mathrm{D}$ de um país; e (3) alta escala de investimentos, ou tamanho do PIB em termos absolutos e disponibilidade de capital para grandes projetos de pesquisa. Os países líderes maximizam as três variáveis; os países difusores concentram-se nas duas primeiras variáveis; países cujos sistemas de C\&T são fragmentados apresentam baixos índices de desenvolvimento nas três categorias. Pertencem ao primeiro grupo países como Estados Unidos, Japão e Alemanha e, em menor escala, Reino Unido, França e Itália. Entre os difusores encontram-se países como Suécia, Dinamarca, Coréia do Sul e Taiwan. Ao terceiro grupo, de países com sistemas de inovação fragmentados, cujas estruturas de C\&T estão ainda em formação, pertencem países como o Brasil e a Argentina. A Figura 1 ilustra, de forma simplificada, as três dimensões estudadas da tipologia de Albuquerque (1996).

Figura 1: Tipologia de SNI's - Representação Gráfica

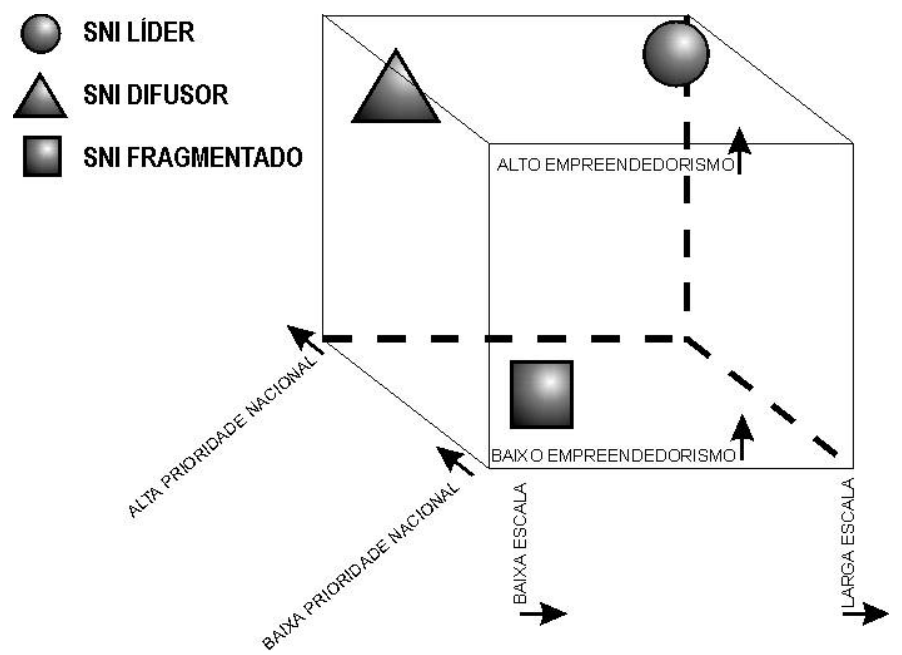

Fonte: adaptado de Albuquerque (1996). 
Conforme se discutiu em Lima (1999), outros aspectos além da pesquisa e desenvolvimento caracterizam o SNI brasileiro como fragmentado. Apesar das pressões competitivas externas, a maioria das empresas nacionais ainda não demonstram vocação para a inovação dos processos intrafirma semelhante ao verificado, por exemplo, nos grupos industriais do sudeste asiático. Aspectos como a formação de redes de pesquisa cooperativa e desenvolvimentos de produtos e processos interfirmas tampouco apresentam dinamismo comparável ao dos países tecnologicamente mais avançados. As condições de financiamento público à $\mathrm{P} \& \mathrm{D}$ mostram-se insuficientes e inadequadas em face das necessidades empresariais, apesar das tentativas recentes do Ministério de Ciência e Tecnologia de estimular mecanismos de inovação. A instabilidade das políticas públicas para esta área resulta em impactos tímidos sobre os indicadores de desenvolvimento científico-tecnológico do complexo industrial do país.

A relação Universidade-Empresa é um dos elementos mais afetados pelas deficiências do Sistema Nacional de Inovação. Esta aproximação, normalmente dificultada pela natureza intrinsecamente distinta dos objetivos da atividade produtiva e da atividade científica, torna-se ainda menos provável de ocorrer espontaneamente no caso brasileiro pelos "desequilíbrios internos ao sistema de ensino-pesquisa", entre os quais Frischtak e Guimarães (1992) ressaltam a "disparidade entre os pesos relativos do setor público e do setor privado [como percentual de participação nos gastos com desenvolvimento tecnológico do país], bem como o desequilíbrio constatado entre os ensinos primário, secundário e universitário". Os autores avaliam que estas deficiências de parte a parte contribuem para a desarticulação do relacionamento U-E, à medida que "de um lado [as universidades] perseguem programas de investigação autônomos e, na maioria das vezes ignoram as necessidades do setor produtivo. De outro lado, as empresas raramente encaram os institutos tecnológicos e as universidades como possíveis supridores de tecnologia ou prestadoras de serviços técnicos" (Frischtak e Guimarães, 1992).

Velho (1996) corrobora esta percepção. Segundo a autora, a indústria nacional historicamente voltou a sua atenção para o exterior, sempre que precisou de tecnologia, no tempo em que os cientistas brasileiros se acostumaram a critérios próprios de relevância da pesquisa; estes critérios raramente contemplavam as necessidades da indústria nacional. Como resultado,

"no Brasil, a articulação entre a universidade e o setor produtivo é relativamente modesta. [Até há pouco tempo atrás], empresários e acadêmicos, como a água e o óleo, não se misturavam. Os primeiros viam os segundos como uns 'sonhadores, desligados da realidade do dia-a-dia, desconhecendo os problemas da produção e do mercado, das relações entre capital 
e trabalho, e mais preocupados com suas carreiras e abstrações próprias de uma imaginação criativa'. Para os acadêmicos, os empresários não estavam dispostos a assumir qualquer responsabilidade no desenvolvimento da ciência brasileira" (Velho, 1996).

Ambas as percepções parecem estar mudando, o que pode ser interpretado como uma tendência de reordenamento do sistema. Por um lado, os empresários estão mais dispostos a assumir responsabilidades na área de pesquisa. Conforme dados dos indicadores nacionais de C\&T, do Ministério de Ciência e Tecnologia (Brasil, 1996), o setor produtivo aumentou a sua participação nos dispêndios de C\&T do país de 22,2\% do total em 1990 para 31,6\% em 1997. Por outro lado, as carências de recursos públicos têm impelido os pesquisadores universitários a direcionar as suas linhas de pesquisa para interesses do setor produtivo (Cassiolato, 1996).

\section{Potencial de Inovação na Bahia: um Panorama}

Seguindo o modelo explicativo de Lundvall (1992), serão traçados breves comentários sobre cinco aspectos do Sistema Baiano de Inovação: (1) elementos peculiares da organização interna das firmas industriais no Estado; (2) a sua inter-relação; (3) condições de financiamento; (4) políticas públicas; e (5) estrutura de ensino, pesquisa e desenvolvimento. Esta caracterização tem por fim contextualizar o ambiente de atuação do elemento de ligação U-E estudado, o IEL-BA.

\section{As Cinco Variáveis do Sistema de Inovação na Bahia}

A partir da década de 90, observa-se um esforço nítido das empresas baianas de reestruturação produtiva com vistas a obter ganhos de qualidade e produtividade. Segundo Lima (1999), o programa Qualidade Bahia registrou que mais de 500 empresas já tinham algum programa de qualidade em 1995, sendo que 39 estavam certificadas pela ISO 9000. Conforme destacam Ferraz, Kupfer e Haguenauer (1995), os níveis de produtividade e a qualidade dos produtos dependem fortemente do nível de educação e qualificação da mão-de-obra. Tomando este indicador como medida do grau de amadurecimento das relações intrafirma na Bahia, verifica-se uma tendência de qualificação de mão-de-obra local a partir da segunda metade da década de 80. Uma análise das 200 maiores indústrias da Bahia, de acordo com levantamento feito pela Federação das Indústrias do estado (Nunes Filho, 1998), aponta uma queda nos níveis de emprego para mão-de-obra não-qualificada em substituição por uma de melhor escolaridade. Em 1985, 81\% 
da mão-de-obra industrial tinha apenas o primário, $14 \%$ curso médio e meros 5\% tinha curso superior. Estas cifras mudaram para $64 \%$, 29\% e 7\%, respectivamente, em 1991.

As empresas industriais baianas pertencem predominantemente aos setores de bens intermediários e de bens tradicionais. No primeiro caso, a integração entre fornecedores de matérias-primas e processadores intermediários e finais é fundamental para a competição por preço. No caso dos bens tradicionais, uma política acertada de compra e boa avaliação do custo/benefício de atualização de equipamentos de produção são determinantes da competitividade (Ferraz, Kupfer e Haguenauer, 1995). O setor de commodities baiano, sobretudo o petroquímico, tem alto grau de articulação vertical para a produção de bens industriais intermediários. A própria estrutura do Pólo Petroquímico de Camaçari foi concebida em torno de centrais de matérias-primas, de manutenção e de utilidades da COPENE, cujos produtos são processados por dezenas de empresas especializadas em agregar valor à cadeia de carbono. $\mathrm{O}$ setor tem enfrentado dois óbices à competitividade: o fracionamento excessivo de pequenas empresas de segunda geração, conforme previamente discutido, e a distância dos mercados consumidores finais. O primeiro obstáculo tem sido minimizado com a sucessão de fusões ocorridas recentemente no setor. O segundo óbice é mais difícil de se contornar no curto prazo. Segundo o depoimento de um consultor de C\&T, coletado em pesquisa de campo por Lima (1999),

"na Bahia, a ausência de produtores de bens finais dificulta a relação interfirma sobretudo pelo distanciamento geográfico. No levantamento de demandas e ofertas de tecnologias na Bahia (Inventec), que coordenei recentemente para o CADCT, vários entrevistados reclamaram da distância entre os centros consumidores; o que se pode fazer é reestruturar o setor para atrair para a Bahia indústrias de bens final, as ditas $3^{\mathrm{a}}, 4^{\mathrm{a}}$ e $5^{\mathrm{a}}$ gerações do Pólo de Camaçari, o que já é uma preocupação do governo".

No tocante às condições de financiamento, Baiardi et al. (1986) argumentam que, dado o peso da economia baiana no PIB do país, o nível de captação de recursos financeiros a partir de agências como FINEP, Banco do Nordeste e CNPq poderia ser muito superior ao obtido até o presente; contudo os mesmos autores reconhecem que a quantidade e qualidade das demandas deixam a desejar. Não se depreendem perspectivas de criação da Fundação de Amparo à Pesquisa da discussão política vigente. Ao que tudo indica, a Bahia continuará a pertencer ao grupo minoritário de estados brasileiros, que ainda não criaram uma agência nos moldes da bem-sucedida Fundação de Amparo à Pesquisa do Estado de São Paulo.

Quanto às políticas públicas de C\&T, não se constata uma atitude proativa do 
governo estadual para com o desenvolvimento da ciência e tecnologia. Em toda a trajetória do sistema, um dos poucos momentos em que se refletiu mais detidamente sobre as perspectivas de avanço das estruturas de C\&T por iniciativa do governo estadual foi por ocasião da edição do Plano de Desenvolvimento Científico e Tecnológico para o Estado da Bahia, na gestão do governador João Durval (Bahia, 1985). Fruto de estímulos do CNPq à consolidação dos Sistemas Estaduais de C\&T (SECT), o plano demonstrou ambiciosa tentativa de elevar a qualificação das equipes técnicas, ampliar e atualizar equipamentos, expandir recursos bibliográficos, apoiar os órgãos de documentação e informação do SECT, apoiar as universidades, sobretudo a Universidade Federal da Bahia (UFBA), e elaborar programas setoriais específicos, contemplando inicialmente os setores de energia, química, agroindústria, materiais, eletromecânica, agrícola, mineral, saúde pública e ambiental. Desde então, a Secretaria de Planejamento, Ciência e Tecnologia tem apresentado poucas iniciativas neste sentido.

Por fim, é também precária a situação do ensino, pesquisa e desenvolvimento no estado. Segundo entrevistas coletadas por Lima (1999), uma das principais deficiências do Sistema Baiano de C\&T está na baixa qualificação e na pequena quantidade dos seus recursos humanos. Os baixos salários oferecidos pela maior parte das instituições de pesquisa afugentam os melhores quadros e são insuficientes para atrair novos talentos. Segundo dados de um inventário recente do Centro de Apoio ao Desenvolvimento de C\&T da Bahia (CADCT), há apenas cerca de 1.300 pesquisadores e técnicos ativos em $P \& D$ na Bahia. Do lado das universidades, tem-se constatado uma migração crescente dos professores mais capacitados das instituições de ensino públicas para as privadas, cujo número aumenta cada ano, mas que, até o momento, não criaram a infra-estrutura necessária para desenvolver pesquisas.

\section{A Relação U-E na Bahia}

São poucos os relatos obtidos de interações bem sucedidas entre universidades e empresas na Bahia. A cooperação privada com universidades estaduais é, conforme depoimentos apresentados por Lima (1999), praticamente inexistente. Uma destas entrevistas relata:

"as universidades estaduais são ainda muito recentes. Têm um corpo diretivo comprometido, mas ainda estão muito distantes de poder proporcionar soluções tecnológicas para tornar o seu meio externo mais competitivo. Para tanto é preciso atingir um determinado nível de capacidade de pesquisa interna e qualificação de recursos humanos; estas universidades ainda estão longe de alcançá-lo. E como não há uma ação de Estado voltada para isto, a atuação destes dirigentes é ainda mais heróica”. 
Mesmo na cinqüentenária Universidade Federal da Bahia, são poucos os acordos registrados de cooperação formal. Fala um dos entrevistados por Lima (1999):

"a universidade entrou num processo progressivo de desvinculação com a realidade até se tornar um enclave na sociedade baiana. Este movimento começa a sofrer agora um processo de reversão. Por questões vinculadas a preconceitos e ausência de visão estratégica, foi negligenciada pelo projeto hegemônico político no Estado da Bahia, o que combinado ao corporativismo característico da instituição levou à situação de isolamento. Tratase de um problema complexo e de difícil solução, ainda que o atual reitorado da universidade busque progressivamente desfazer este modelo, estabelecendo canais mais articulados com a sociedade organizada e o governo".

Do ponto de vista dos níveis de interação de Bonaccorsi e Piccaluga (1994), Lima (1999) verificou o que segue.

- Relações pessoais informais. Não há registros oficiais sobre o nível de interação informal entre as universidades e as empresas, dado o seu caráter suprainstitucional; contudo há razões para crer que este mecanismo constitui a forma mais difundida de cooperação U-E no estado. Mesmo professores em regime de dedicação exclusiva (DE) buscam, em consultorias a empresas, uma forma de manter contato com a realidade prática dos seus objetos de estudo. Esta tendência é ainda maior em áreas, cuja natureza aplicada do conhecimento aumenta o potencial de prestação de serviços à atividade produtiva, como é o caso das engenharias e da administração.

- Instituições de ligação. Além das estruturas internas da UFBA, algumas outras entidades orbitam os centros acadêmicos da universidade, flexibilizando o repasse de recursos por meio de convênios e prestação de serviços. O Instituto Euvaldo Lodi, objeto de estudo deste trabalho, tem sido uma das pontes mais proativas deste processo na Bahia. A articulação promovida por estes agentes externos ainda não parece suficiente para minimizar a falta de informações que persiste no meio acadêmico e empresarial.

- Acordos formais. São encontrados indicadores de esforço maior de formalização da relação com empresas por parte da UFBA em documentos a partir da década de 90 . Além das resoluções do conselho formalizadas no começo da década, o então reitor Luis Felippe Serpa afirmou, durante a cerimônia de lançamento do Fórum de Tecnologia da Bahia, em 1996, que "a UFBA, desde 94, vem não só preocupada, mas estimulando esse tipo de discussão e cooperação entre as três instâncias mais importantes [...], que são o governo do estado, o sistema produtivo e as universidades" (Lima, 1999). 
- Estruturas fixas de interação. As incubadoras de empresa de base tecnológica constituem a forma mais difundida de estruturas permanentes de interação Universidade-Empresa no estado. A Bahia está entre os cinco maiores estados em número de empresas incubadas, tendo uma previsão de mais de 50 empresas até o final de 1999. Estão em operação cinco incubadoras, três delas com a parceria direta da Universidade Federal da Bahia. Este número tende a crescer, principalmente no interior do estado, onde a demanda por incubadoras de caráter agroindustrial é crescente.

Em resumo, os poucos casos de cooperação na Bahia indicam que a sociedade local, a exemplo do restante do país, parece estar começando a despertar para o potencial da interação U-E. Tanto do lado das empresas, que enxergam nos recursos a fundo perdido uma oportunidade de atualização tecnológica, quanto do lado das universidades, que vêem na indústria a chance de minimizar carências materiais, a predisposição à interação dá sinais de estar em evolução. Esse contexto favorável ajuda a explicar o respaldo obtido pelo Instituto Euvaldo Lodi nos últimos três anos, ao eleger como missão promover o desenvolvimento tecnológico mediante o estímulo à relação U-E.

\section{O IEL Enquanto Agente Indutor}

O presente estudo de caso abrange o período de 1996 a 1998, correspondente ao período em que o IEL se voltou mais agressivamente para aspectos tecnológi$\cos$ da relação Universidade-Empresa. Esta seção se propõe caracterizar brevemente alguns dos principais programas de desenvolvimento tecnológico da entidade, com ênfase nos programas de articulação direta da relação U-E, particularmente no programa Fórum de Tecnologia.

Os programas do IEL apresentam, pelo menos formalmente, vasto leque de parcerias com organismos do sistema de C\&T. Os convênios assinados com as instituições do sistema de C\&T representaram uma entrada de recursos da ordem de meio milhão de reais em 1997 e o dobro deste montante no ano seguinte. Mais de 50 entidades de C\&T estão formalmente vinculadas aos programas do IEL, seja como patrocinadoras, seja como membros dos conselhos consultivos e comitês gestores. Essa capacidade de articulação local elevou o instituto à categoria de secretaria executiva da Subcomissão Regional do Programa de Apoio à Capacitação Tecnológica na Indústria (PACTI), no âmbito do Fórum de Tecnologia da Bahia. Esta articulação abriu um canal de interlocução direta com funcionários do Ministério de Ciência e Tecnologia à frente dos programas de difusão tecnológica no país. Algumas ações locais do ministério passaram a ser coorde- 
nadas pelo instituto, a exemplo das palestras de divulgação do Programa de Apoio ao Desenvolvimento Científico e Tecnológico (PADCT), do treinamento de uso do Formulário Único de Propostas e da vinda para o instituto de um escritório de promoção de negócios da FINEP.

Os programas do IEL podem ser subdivididos em dois grandes grupos: programas temáticos e programas de articulação direta U-E. Entre os programas temáticos, destacam-se a intermediação de estágios supervisionados, os programas Qualidade Bahia e Qualidade na Engenharia e o programa Bahia Design. Até meados da década de 90 o IEL-BA era conhecido quase exclusivamente por seus serviços a estudantes interessados em estágios. Esta percepção da comunidade tem mudado à medida que os programas de articulação direta entre universidade e empresa consolidam os demais aspectos da missão institucional da entidade.

\section{Programas de Articulação Direta da Relação U-E}

\section{Programa Incubadoras de Empresas}

O PROINC foi concebido como reforço institucional no desenvolvimento de empresas incubadas. O programa entrou em operação em fins de 1994, com o objetivo de fomentar a criação e a consolidação de empresas de base tecnológica, a partir da estrutura de incubadoras pré-existente e a ser expandida no estado. Naquela época, apenas a INCUBATEC, no CEPED, havia sido criada. A sua atuação tem norteado a abertura e articulação de novas incubadoras. Fazem parte do conselho do programa 14 entidades governamentais, empresariais e de ensino-pesquisa.

A secretaria executiva do PROINC se propõe fazer a sensibilização de atores com potencial de constituição de incubadoras no estado. Para tanto, na fase de estudos, o programa elege facilitadores locais, promove um levantamento da demanda e coordena a definição de parceiros interessados na constituição de um novo projeto de incubadora. Cada parceiro deve definir uma forma de contrapartida ao projeto, seja na modalidade de recursos financeiros, seja por meio de instalações físicas ou facilidades logísticas. Após as reformas das instalações da entidade que hospedará os incubados, é promovido o lançamento do edital de convocação das empresas candidatas; é feita então a seleção de propostas e a supervisão da assinatura dos contratos.

Lima (1999) sugere que o fato de algumas das incubadoras estarem localizadas dentro do ambiente universitário tende a aumentar a interação U-E. Além de trazer empresários para dentro do ambiente acadêmico, as incubadoras monta- 
das em meio à infra-estrutura universitária estimulariam a conversão de professores, pesquisadores e alunos em empreendedores.

A maioria dos fóruns de incubadoras existentes no país (São Paulo, Rio de Janeiro, Minas Gerais e Paraná) foram criados como uma conseqüência da necessidade de articulação posterior à difusão de incubadoras; o PROINC, pelo contrário, surgiu antes da difusão das incubadoras locais. Este fato permitiu ao programa coordenar a implantação de novos projetos de forma mais articulada, prestando assistência aos novos empreendimentos, desde a sua concepção até a assinatura dos contratos com as empresas incubadas. O PROINC esteve presente na criação e articulação de 8 das 9 incubadoras existentes no estado. Está em processo de implantação um sistema de comunicação em rede entre as incubadoras (Intranet), o qual deverá permitir a troca de informações em tempo real, visando à otimização dos recursos disponíveis.

\section{Rede de Tecnologia da Bahia}

Inaugurada em 23 de setembro de 1998, a RETEC é um dos programas mais recentes do IEL. A rede baiana foi concebida originalmente a partir do modelo de intermediação de serviços tecnológicos da Rede de Tecnologia do Rio de Janeiro. O projeto original foi, contudo, adaptado às condições locais de oferta e demanda, dando origem a um programa com peculiaridades próprias, inéditas no sistema IEL. Ao contrário da entidade carioca, que obtém sustentação sobretudo dos associados no lado da oferta tecnológica, a RETEC busca o apoio entre os interessados no lado da demanda, contando com a parceria de empresas locais e nacionais. Além da oferta de grupos de pesquisa na UFBA, a RETEC busca cadastrar consultores com experiência em desenvolvimento tecnológico em empresas do Pólo e do CIA. Seu principal objetivo é "promover a efetiva integração de oferta e demanda tecnológica entre os diversos agentes econômicos, sociais e institucionais que atuam no estado". Estrategicamente, o projeto adota a postura de priorizar o segmento de pequenas e médias empresas, tendo em vista que o posicionamento próprio das grandes empresas quanto a questões tecnológicas prescinde, na maioria dos casos, de intermediários tecnológicos.

Os principais serviços oferecidos pela RETEC são: (1) intermediação de consultores e instituições de pesquisa e desenvolvimento, que se pode dar por meio da consulta a um cadastro de especialistas ou pela descrição de um problema tecnológico, deixando a cargo da RETEC a identificação de pessoas físicas ou jurídicas em nível estadual, nacional e internacional mais adequadas para atender à demanda; (2) intermediação de serviços laboratoriais; (3) informações sobre financiamento para capacitação tecnológica; (4) informação tecnológica sobre processos, produtos, marcas e patentes; (5) promoção de transferência de tecno- 
logia. Como os demais programas do instituto, há preocupação com atividades de divulgação para o setor produtivo e a promoção de eventos de sensibilização para a importância da inovação tecnológica.

A RETEC capta a demanda tecnológica empresarial por três canais: por meio das consultas à página na Internet (vide www.fieb.org.br/retec), pelos balcões de atendimento do SEBRAE e do Banco do Nordeste e por meio do escritório no IEL, pessoalmente ou por telefone. Está em negociação a capilarização da oferta de serviços mediante o uso do sistema SAC - Serviço de Atendimento ao Cidadão, do Governo do Estado. A estrutura operacional da RETEC é a segunda maior entre os programas do instituto, depois do Programa de Estágios. Conta com um coordenador doutor, em tempo integral, e um coordenador com mestrado, em tempo parcial, uma secretária e quatro estagiários. A IBM doou quatro computadores e um servidor ao programa, permitindo o controle pleno dos acessos via Internet e a gestão integrada do sistema de informações da rede.

Os poucos meses de operação da rede até a finalização deste estudo tornam precipitadas quaisquer avaliações de resultados. Há indícios, porém, de que o programa vem atender a uma grande carência dos empresários baianos que, utilizando a expressão de um pequeno industrial durante a apresentação do projeto, "não sabiam nem em que pé de caboclo chorar", quando tinham problemas de natureza tecnológica. A experiência acadêmica e prática dos coordenadores do programa é elemento chave para o seu sucesso; cabe-lhes diagnosticar problemas tecnológicos, nem sempre bem formulados pelos empresários demandantes, e identificar, no sistema local ou nacional de C\&T, os consultores acadêmicos ou empresariais que possam resolvê-los. O projeto oferece serviços de diagnósticos de gargalos tecnológicos a um custo de $\mathrm{R} \$ 1.200,00$ para pequenas e médias empresas. A demanda tem surpreendido os coordenadores do serviço, o qual vem consolidando-se como porta de entrada, para que os empresários conheçam diversas outras iniciativas do IEL, tais como o Programa de Produtividade Industrial, a Rede Baiana de Metrologia e Ensaios, e o Bahia Design. Problemas diagnosticados que sejam da competência de cada um destes programas lhes são encaminhados pela rede.

A superintendência do IEL parece reconhecer, entretanto, os limites de articulação de um programa com tamanhas pretensões em um sistema de C\&T fragmentado como o baiano. Segundo entrevista recente do atual superintendente, "ante as adversidades ambientais de C\&T na Bahia, é preciso ter em mente as limitações deste serviço. A RETEC certamente não vai trazer nenhuma mudança cultural profunda; será um mecanismo auxiliar de promover a competitividade tecnológica dos pequenos e médios empresários que tiverem adquirido a maturidade de usufruir dos seus serviços" (Lima, 1999). 


\section{O Fórum de Tecnologia da Bahia}

Entre os programas com sede no IEL, nenhum outro promove a interação Universidade-Empresa de forma tão inovadora quanto o Fórum de Tecnologia da Bahia (FORUMTEC). O impacto dos resultados apresentados em menos de dois anos de operação, assim como os baixos recursos necessários à sua manutenção, sugerem uma descrição mais aprofundada desta forma de articulação UE como alternativa viável em sistemas de $\mathrm{C} \& \mathrm{~T}$ enfraquecidos por deficiências institucionais e falta de coordenação interinstitucional.

O fórum tem o objetivo genérico de "articular as instituições que compõem o Sistema de Ciência e Tecnologia do estado". Ao contrário da RETEC, que atende a demandas pontuais de empresários e busca soluções de curto prazo junto a consultores universitários ou privados, as atividades do fórum são voltadas principalmente para a geração de projetos cooperativos que captem recursos para o desenvolvimento tecnológico local. Além desta função, que envolve diretamente a relação U-E, o fórum tem como funções a difusão de informações tecnológicas e a sensibilização da comunidade para os temas dos seus Grupos de Trabalho (GTs). O Comitê Gestor é formado por 23 entidades de governo, do setor privado e da academia, diretamente envolvidas na geração e difusão de C\&T. Reúne-se mensalmente para deliberar questões operacionais resultantes da ação da Secretaria Executiva e dos Grupos de Trabalho, bem como estabelecer novos temas, em que a capacidade de oferta das universidades vem se adequando às necessidades tecnológicas de longo prazo das empresas, de modo a sugerir a submissão de projetos cooperativos no âmbito dos GTs.

A Secretaria Executiva é a instância de apoio operacional ao fórum, com sede no Instituto Euvaldo Lodi. É composta por um coordenador em tempo integral e um bolsista. Tem as atribuições de articular e coordenar as ações dos Grupos de Trabalho, assessorar as reuniões do Comitê Gestor, executar os serviços de divulgação, incluindo a manutenção de uma home page, organizar eventos e gerenciar um sistema de informações a partir de uma base de dados de empresas.

Os GTs são a instância operacional do fórum, em que ocorre a articulação UE de forma mais explícita. Os grupos de Automação Industrial, Transformação Plástica e Tecnologias Limpas têm sido os mais bem sucedidos em termos de recursos obtidos junto ao Ministério de Ciência e Tecnologia. Quando a necessidade de criação de novo grupo de trabalho é detectada pelo Comitê Gestor, ou outro ator do sistema de C\&T que procure a Secretaria Executiva, cada instituição membro designa um representante para compor o GT. É então convocada uma primeira reunião do grupo para a escolha dos coordenadores das subcomissões temáticas; a partir da capacidade de oferta de conhecimento dos integran- 
tes, empresas são convidadas a comporem as subcomissões do seu interesse. Com base nesta estrutura, são submetidos projetos cooperativos em que se soma a experiência acadêmica dos coordenadores e entidades de $\mathrm{P} \& \mathrm{D}$ às contrapartidas das empresas, cuja participação no grupo sinaliza às fontes financiadoras o grau de envolvimento privado com os resultados da atividade do grupo.

Além de projetos submetidos às linhas de financiamento (PADCT, Banco do Nordeste, FINEP, MCT), são também produtos dos grupos de trabalho a sensibilização da comunidade e a difusão de informações tecnológicas. A sensibilização e a mobilização da comunidade de C\&T se dão em cursos, palestras e workshops. Tais eventos visam a agregar empresas potencialmente interessadas em participar dos conselhos empresariais dos grupos de trabalho e a gerar recursos para manutenção de um fundo de sensibilização para o tema do GT. A difusão de informações ocorre durante os encontros dos Grupos de Trabalho e do Comitê Gestor, ou por meio do sistema de informações, mantido pela secretaria executiva e disponibilizado via Internet.

São criadas subcomissões temáticas, quando o tema principal de um GT é amplo demais para agregar as demandas específicas das diversas empresas interessadas. Temas como automação industrial, conservação de energia e agroindústria podem gerar projetos em processos contínuos ou discretos, envolver questões vinculadas à energia elétrica ou térmica, ou dizer respeito a apenas dois subsetores, como, por exemplo, fruticultura e produção de bebidas alcoólicas. As subcomissões temáticas são coordenadas por especialistas das respectivas áreas de competência, os quais não pertencem necessariamente à mesma instituição de ensino, pesquisa e desenvolvimento. A estes coordenadores cabe o papel de conduzir as reuniões operacionais e ser o interlocutor com o conselho empresarial do grupo de trabalho.

O êxito do FORUMTEC deve ser mensurado nas linhas em que se propõe atuar: geração de projetos cooperativos, ou sensibilização para a inovação e difusão de informações. No tocante a projetos, foram aprovadas três propostas submetidas por grupos de trabalho do fórum às duas rodadas do Componente de Desenvolvimento Tecnológico (CDT) do PADCT III. Na primeira rodada foi aprovado o projeto plataforma do GT de Automação Industrial, no valor total de $\mathrm{R} \$ 140.000,00$, dos quais um terço oferecido como contrapartida de sete empresas do Pólo Petroquímico de Camaçari. Liderado pelo Departamento de Engenharia Mecânica da UFBA, a articulação envolveu ainda os Departamentos de Engenharia Química e Elétrica daquela universidade, a Fundação Escola Politécnica, o Centro de Tecnologia Industrial do Serviço Nacional da Indústria (CETIND/SENAI), o Centro Federal de Educação Tecnológica (CEFET) e a Universidade Salvador (UNIFACS). Com os recursos obtidos, foram promovidos 
debates em workshops e seminários que resultarão em propostas ao PADCT de novos projetos cooperativos, adaptados às necessidades locais. Paralelamente está sendo contratada, junto ao Laboratório de Gestão Empresarial da Escola Politécnica, uma pesquisa sobre automação com mais de uma centena de empresas.

A segunda rodada do CDT contemplou mais dois projetos gestados em grupos de trabalho do fórum. O primeiro, do tipo cooperativo específico, obteve recursos da ordem de $\mathrm{R} \$ 240.000,00$, dos quais mais de $60 \%$ são contrapartida de uma empresa local interessada em firmar parceria com o CETIND, a UFBA e a Universidade Federal da Paraíba (UFPB) para o desenvolvimento de produtos plásticos. O segundo, do tipo plataforma, é voltado para a difusão de tecnologias limpas. Coordenado pelo Departamento de Engenharia Sanitária da UFBA, o projeto envolve outras cinco unidades da universidade, a UNIFACS, o CEFET, o Centro de Recursos Ambientais (CRA) e quatro empresas baianas. O valor total do projeto é da ordem de $\mathrm{R} \$ 120.000,00$, dos quais quase um terço é obtido sob a forma de contrapartida das empresas envolvidas.

A geração de projetos cooperativos é a medida mais tangível dos resultados do fórum. Durante a elaboração das três propostas aprovadas em 1998, foram articulados dezenas de departamentos universitários, centros de P\&D e empresas, em um esforço ímpar de integração U-E. Outros tantos atores foram envolvidos por projetos rejeitados em primeira instância ou ainda não submetidos, como no caso dos grupos de trabalho em sisal e agroindústria. A presença de um agente promotor de negócios da FINEP com escritório no IEL tende a dinamizar ainda mais essas relações, tendo em vista a diversificação das fontes de financiamento.

Em seu planejamento para 1999, o FORUMTEC prevê a criação de oito novos grupos de trabalho. Se estes obtiverem um sucesso semelhante aos primeiros, a visibilidade auferida por este mecanismo de desenvolvimento tecnológico ante as empresas e entidades de pesquisa poderá tornar o FORUMTEC uma referência local para articulação em C\&T, o que virá a suprir parcialmente a carência histórica de uma estabilidade política no âmbito estadual. Tal representatividade poderia acrescentar uma dimensão estratégica às reuniões operacionais do Comitê Gestor, tornando-o um espaço adequado à formulação de propostas de desenvolvimento e estabelecimento de prioridades em ciência e tecnologia. Esta evolução do fórum ainda é uma incógnita. Fala um dos entrevistados por Lima (1999):

"a adesão voluntária a mecanismos de representação na Bahia é muito frágil. É difícil manter uma consistência neste processo. O fórum enquanto instância de mobilização tem sido um sucesso. Mas até quando? $\mathrm{O}$ apoio do estado será decisivo para a expansão do programa, transformando-o em um espaço de discussão de políticas científico-tecnológicas fundamentadas nas expectativas da academia e do setor privado. Sem este apoio, o 
programa continuará apenas como um canal de articulação institucional entre o setor produtivo e as universidades" (entrevista).

\section{CONCLUSÓES}

A aproximação entre universidades e empresas tem sido uma forma encontrada por vários países de adequar os recursos humanos formados à realidade do mercado, bem como estimular um ambiente em que geradores e usuários de conhecimento possam encontrar melhores aplicações ao aprendizado institucional em prol do aumento da capacidade competitiva da sua sociedade perante outras nações. Esta aproximação vem sendo estimulada sob diversas formas, desde consultorias de docentes e prestação de serviços técnicos, até complexas estruturas fixas de interação, tais como parques tecnológicos e incubadoras de empresas no âmbito universitário.

Os estudos sobre Sistemas Nacionais de Inovação oferecem uma perspectiva teórica adequada à investigação da interação U-E, uma vez que a sua análise contempla não apenas a dinâmica interna destas três esferas institucionais, como também os fluxos de informações e recursos em seus inter-relacionamentos. Atentos a estes aspectos institucionais da inovação, os países mais bem sucedidos economicamente apresentam um histórico de políticas públicas voltadas para o desenvolvimento da sua infra-estrutura educacional e econômica, que lhes confere hoje a liderança tecnológica ou pelo menos grande capacidade de acompanhar a fronteira do desenvolvimento técnico.

Em Sistemas Nacionais de Inovação fragmentados, as condições institucionais para o aprendizado e difusão de conhecimento são precárias. Países como o Brasil investem pouco em C\&T, tanto em termos absolutos quanto relativos; as empresas participam com parcela minoritária do total deste investimento, revelando baixo comprometimento institucional com a questão tecnológica. Do lado das universidades, recursos escassos são direcionados primordialmente para o ensino, tendo demonstrado uma intensidade de pesquisa, salvo em centros de excelência isolados.

Estas questões foram enfocadas no contexto do Sistema Estadual de C\&T na Bahia, propondo-se avaliar a atuação de um agente indutor da relação Universidade-Empresa no estado, o Instituto Euvaldo Lodi, entre 1996 e 1998. A caracterização ambiental da Bahia apontou alguns aspectos do sistema local de C\&T que dificultam particularmente a relação U-E, quais sejam: a estrutura industrial concentrada em produtores de commodities ou bens tradicionais tecnologica- 
mente pouco desenvolvidos; a descontinuidade dos mecanismos de apoio do governo estadual; a ausência de critérios claros para a alocação dos recursos financeiros estaduais em C\&T e a baixa qualificação dos recursos humanos disponíveis.

O IEL apresenta mecanismos inovadores para incrementar a relação U-E. Estes mecanismos encontram, por um lado, um discurso favorável ao seu crescimento e consolidação; por outro, há condições práticas pouco adequadas à difusão tecnológica: baixo grau de estruturação tecnológica intrafirma; baixo grau de interação interfirma; condições insuficientes de financiamento; falta de políticas públicas específicas e estáveis e a precariedade da estrutura local de ensinopesquisa.

Este trabalho buscou fornecer indícios qualitativos de que a atuação de um agente indutor da relação U-E, embora longe de solucionar os problemas estruturais de C\&T em sistemas fragmentados, pode criar um ambiente fértil em idéias e projetos que contribua para amenizar as deficiências institucionais típicas de países em desenvolvimento. Com relativamente poucos recursos, é possível criar mecanismos que induzam a interação permanente entre pesquisadores e empresários, a fim de implementar uma cultura de busca por novas formas de combinar velhos fatores.

\section{Referências Bibliográficas}

\section{ALBUQUERQUE, E.}

Sistema nacional de inovação no Brasil : uma análise introdutória a partir de dados disponíveis sobre C\&T. Revista de Economia Política, v. 16, n. 3, p. 56-71, jul./ set. 1996.

BAIARDI, A. et al.

A ciência e a tecnologia no Estado da Bahia. Salvador : Fundação João Mangabeira, 1986.
BONACCORSI, A.;

PICCALUGA, A.

A theoretical framework for the evaluation of university-industry relationships.

R\&D

Management, v. 24, n. 3, p. 229247, 1994.

BRASIL.

Ministério de Ciência e Tecnologia. Indicadores nacionais de C\&T 1990-1995. Brasília, 1996. 
CASSIOLATO, J. E.

A relação universidade e instituições de pesquisa com o setor industrial : uma abordagem a partir do processo inovativo e lições da experiência internacional. Brasília : Sebrae, 1996.

\section{CHRISTENSEN, J.}

The role of finance in national systems of innovation. In: LUNDVALL, B. (Ed.). National systems of innovation : towards a theory of innovation and interactive learning. London : Pinter Publishers, 1992. p. 147168.

\section{ETZKOWITZ, H.}

Enterprises from science : the origins of science-based regional academic development. Minerva, v. 31, n. 3, 1993.

FERRAZ, J. C.;

KUPFER, D.;

HAGUENAUER, L.

Made in Brazil : desafios competitivos para a indústria. Rio de Janeiro : Campus, 1995.

FIEB.

As 200 maiores indústrias da Bahia. Salvador, 1991.
FREEMAN, C.

Technology and economic performance : lessons from Japan. London: Pinter Publishers, 1987.

Formal scientific and technical institutions in the national system of innovation. In: LUNDVALL, B. (Ed.). National systems of innovation : towards a theory of innovation and interactive learning. London : Pinter Publishers, 1992. p. 169-187.

FRISCHTAK, C.;

GUIMARÃES, E. A.

O sistema nacional de inovação : estratégia para o seu reordenamento. [S.1. : s.n.], 1992. p. 6392.

\section{GELSING, L.}

Innovation and the development of industrial networks. In: LUNDVALL, B. (Ed.). National systems of innovation : towards a theory of innovation and interactive learning. London : Pinter Publishers, 1992.p. 117-128.

\section{GJERDING, A. N.}

Work organization and the innovation design dilemma. In: LUNDVALL, B. (Ed.). National systems of innovation : towards a theory of innovation and interactive learning. London : Pinter Publishers, 1992.p. 95-115. 
GREGERSEN, B.

The public sector as a pacer in national systems of innovation. In: LUNDVALL, B. (Ed.). National systems of innovation : towards a theory of innovation and interactive learning. London : Pinter Publishers, 1992.

LIMA, M.

Inserção de um agente indutor da relação universidadeempresa em um sistema de inovação fragmentado. Salvador, 1999. Dissertação (Mestrado em Administração) - Escola de Administração, Universidade Federal da Bahia.

LUNDVALL, B.

Introduction. In: . National systems of innovation : towards a theory of innovation and interactive learning. London : Pinter Publishers, 1992. p. 1-19.

NUNES FILHO, P. S.

Desenvolvimento industrial da Bahia : uma abordagem sócioeconômica. In: Prêmio FIEB de monografias sobre o desenvolvimento industrial na Bahia. Salvador : FIEB, 1998.
PLONSKI, G. A.

Cooperação universidade-empresa na Iberoamérica : estágio atual e perspectivas. In: $18^{\circ}$ SIMPÓSIO DE GESTÃO DA INOVAÇÃO TECNOLÓGICA (1994 : São Paulo). Anais... São Paulo : USP/NPGCT/FIA, 1994. p. 361376.

REIS, D.

Em busca da inovação tecnológica : motivações e barreiras para a cooperação. Revista Educação \& Tecnologia, v. 2, n. 3, p. 38-54, ago. 1998.

STAL, E.

A contratação empresarial da pesquisa universitária. In: $18^{\circ}$ SIMPÓSIO DE GESTÃO DA INOVAÇÃO TECNOLÓGICA (1994 : São Paulo). Anais... São Paulo : USP/NPGCT/FIA, 1994. p. 391-415.

VELHO, S.

Relações universidade-empresa : desvelando mitos. Campinas : Autores Associados, 1996. 